\title{
Leptin promotes IL-18 secretion by activating the NLRP3 inflammasome in RAW 264.7 cells
}

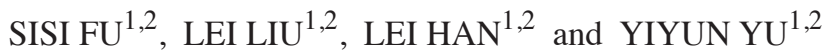 \\ ${ }^{1}$ Division of Rheumatology, Huashan Hospital; ${ }^{2}$ Institute of Rheumatology, \\ Immunology and Allergy, Fudan University, Shanghai 200040, P.R. China
}

Received February 25, 2017; Accepted August 31, 2017

DOI: $10.3892 / \mathrm{mmr} .2017 .7797$

\begin{abstract}
Leptin is a cytokine-like hormone secreted by adipocytes, which serves to control energy expenditure and metabolism. In addition, leptin may modulate the innate and adaptive immune responses. The innate immune cell sensor nucleotide-binding oligomerization domain-like receptor family pyrin domain-containing 3 (NLRP3) inflammasome is mainly expressed in myeloid immune cells, including macrophages. The NLRP3 inflammasome serves a pivotal role in the development and maintenance of autoimmunity and inflammation. The expression levels of caspase-1, apoptosis-associated speck-like protein containing a CARD, interleukin (IL)-18, IL-1 $\beta$ and leptin are significantly reduced in the white adipose tissue of nonsteroidal anti-inflammatory drug-activated gene-1 transgenic mice. However, the association between leptin and the NLRP3 inflammasome has not yet to be determined. The aim of the present study, was to explore the role of leptin on NLRP3 inflammasome. In order to do this, IL-1 $\beta$ and IL-18 expression levels were investigated in RAW 264.7 cells after incubation with leptin of increasing doses by Elisa or reverse transcription-quantitative polymerase chain reaction, and to assess whether IL-1 $\beta$ and IL-18 were affected after caspase-1 activity being inhibited by an inhibitor or by silencing NLRP3 expression. The results of the present study demonstrated that leptin enhanced the mRNA and protein expression levels of IL-18 in RAW 264.7 cells via activation of the NLRP3 inflammasome. This is achieved partly by enhancing the production of reactive oxygen species and $\mathrm{K}^{+}$efflux. Therefore, leptin may be considered a novel activator and modulator of the NLRP3 inflammasome.
\end{abstract}

Correspondence to: Dr Yiyun Yu, Division of Rheumatology, Huashan Hospital, Fudan University, 12 Middle Urumqi Road, Shanghai 200040, P.R. China

E-mail: 13788978206@163.com

Key words: leptin, nucleotide-binding oligomerization domain-like receptor family pyrin domain-containing 3, inflammasome, cytokine

\section{Introduction}

The nucleotide-binding oligomerization domain-like receptor family pyrin domain-containing 3 (NLRP3) inflammasome can stimulate the innate or adaptive immune system in response to certain signals, including endogenous metabolites and microorganisms. It is understood that the underlying mechanism employed by the NLRP3 inflammasome involves the recruitment of apoptosis-associated speck-like protein containing a CARD (ASC) and caspase-1. As a result of inflammasome activation, the proinflammatory cytokines interleukin (IL)-1 $\beta$ and IL-18 are released via pyroptosis and proteolytic cleavage (1). Activators of the NLRP3 inflammasome are heterogeneous, ranging from self-originating crystals, such as monosodium urate monohydrate, uric acid, glucose and adenosine 5 'triphosphate (ATP) to environment-derived aluminum hydroxide, silica and asbestos, as well as pathogenic molecules $(2,3)$. How such structurally diverse molecules activate the NLRP3 inflammasome is yet to be determined; however, it appears that $\mathrm{K}^{+}$efflux and reactive oxygen species (ROS) may serve pivotal roles in activation of the NLRP3 inflammasome $(3,4)$. NLRP3 is usually expressed in myeloid cells, including monocytes, macrophages and dendritic cells; recently it has been revealed that NLRP3 is also expressed in T helper (Th) 1 (5), Th2 (6) and Th17 (7) cells. Providing the association between NLRP3 activation and numerous pathological conditions, including Muckle-Wells syndrome (8), Alzheimer's disease (9), type 2 diabetes (10), as well as autoimmune disorders, such as experimental autoimmune encephalitis (7) and systemic lupus erythematosus (11), increasing efforts to clarify the underlying molecular mechanism are being made.

Secreted by adipocytes, leptin is a cytokine-like hormone that has been reported to control energy expenditure and metabolism, and modulate the innate and adaptive immune responses. The activation of natural killer cells, chemotaxis of neutrophils, and secretion of tumor necrosis factor (TNF)- $\alpha$, IL-6 and IL-12 from macrophages (12) also involves leptin. Additionally, leptin also promotes Th17 cell responses (13) and downregulates the number of $\mathrm{T}$ regulatory cells (14). Previously, it was demonstrated that the mRNA and protein expression levels of caspase-1 and ASC were significantly reduced, in addition to reduced expression levels of IL-18, IL-1 $\beta$, leptin and macrophage infiltration markers, within 
white adipose tissue of nonsteroidal anti-inflammatory drug-activated gene-1 transgenic mice (15). These findings have indicated an association between leptin and the NLRP3 inflammasome within macrophage cells. The present study demonstrated that activation of the NLRP3 inflammasome was promoted by an increase in ROS synthesis and $\mathrm{K}^{+}$efflux in response to leptin, which resulted in an increase in IL-18 secretion within RAW 264.7 cells. Leptin may therefore be considered a novel activator and a potential modulator of the NLRP3 inflammasome.

\section{Materials and methods}

Cell culture. RAW 264.7 murine macrophage cells (The Cell Bank of Type Culture Collection of the Chinese Academy of Sciences, Shanghai, China) were cultured in Dulbecco's modified Eagle's medium (DMEM, low glucose) supplemented with $10 \%$ fetal bovine serum, $100 \mathrm{ng} / \mathrm{ml}$ streptomycin and $100 \mathrm{U} / \mathrm{ml}$ penicillin (Gibco; Thermo Scientific, Inc., Waltham, $\mathrm{MA}, \mathrm{USA})$ at $37^{\circ} \mathrm{C}, 5 \% \mathrm{CO}_{2}$ and humidity. Various doses of leptin $(10,100$ and $500 \mathrm{ng} / \mathrm{ml}$; PeproTech China, Suzhou, China) were added and the cells were cocultured for $24 \mathrm{~h}$ in the presence or absence of Ac-YVAD-cmk (18.4 $\mu \mathrm{M}$; Sigma-Aldrich; Merck KGaA, Darmstadt, Germany), $\mathrm{KCl}$ $(100 \mu \mathrm{M})$ or diphenyleneiodonium chloride (DPI; $50 \mu \mathrm{M}$, Sigma-Aldrich; Merck KGaA). Lipopolysaccharide (LPS, 100 ng/ml, Sigma-Aldrich; Merck KGaA) and/or adenosine 5 'triphosphate (ATP, 5 mM, Sigma-Aldrich; Merck KGaA) were cultured for $3 \mathrm{~h}$ respectively and used as positive controls. Cells were centrifuged at $400 \mathrm{x} \mathrm{g}$, for $5 \mathrm{~min}, 4^{\circ} \mathrm{C}$, and supernatants and sediments were collected and analyzed by ELISA or reverse transcription-quantitative polymerase chain reaction (RT-qPCR).

Flow cytometric analysis. Caspase-1 activity was detected using a Fluorochrome-Labeled Inhibitor of caspase-1 kit: FAM-FLICA ${ }^{\circledR}$ Caspase assay kit (cat. no. 655) (ImmunoChemistry Technologies, LLC, Bloomington, MN, USA). ROS synthesis was investigated using a ROS detection assay kit, CFDA Cellular ROS Detection assay kit (cat. no. ab113851, Abcam, Shanghai, China). THBP was used as a positive control. All kits were performed according to the manufacturer's protocol. Results were analyzed using a FACSCanto FlowJo 7.6 (BD Biosciences, Franklin Lakes, CA, USA).

Cytokine measurement. IL-1 $\beta$ and IL-18 expression levels in the supernatant of RAW 264.7 cells were measured using ELISA kits (Mouse IL-18 cat. no. BMS618, Mouse IL-1 $\beta$ cat. no. BMS6002) and were purchased from eBioscience; Thermo Fisher Scientific, Inc., according to the manufacturer's protocols.

RNA isolation, $c D N A$ synthesis and reverse transcriptionquantitative polymerase chain reaction ( $R T-q P C R)$. Total cellular RNA was isolated using TRIzol reagent (Invitrogen; Thermo Fisher Scientific, Inc.) according to the manufacturer's protocol. cDNA was synthesized from $500 \mathrm{ng}$ total RNA in 10 ul volume using a Superscript kit (Invitrogen; Thermo Fisher Scientific, Inc.). The conditions used were $37^{\circ} \mathrm{C}$ for
$15 \mathrm{~min}$ and $85^{\circ} \mathrm{C}$ for $5 \mathrm{sec}$. RT-qPCR reactions were performed using 1ul cDNA, 10 ul SYBR Green mater mix (Bio-Rad Laboratories, Inc., Hercules, CA, USA), 2 ul of primer mix in a total volume of $20 \mathrm{ul}$. Thermocycling conditions were set up as follows: $5 \mathrm{~min}$ at $95^{\circ} \mathrm{C}, 40$ cycles of denaturation $(5 \mathrm{sec}$ at $95^{\circ} \mathrm{C}$ ), and combined annealing/extension $\left(34 \mathrm{sec}\right.$ at $64^{\circ} \mathrm{C}$ ). The housekeeping gene GAPDH was used as the internal standard. Analysis of relative gene expression data using the $2^{-\Delta \Delta \mathrm{Cq}}$ method (16). RT-qPCR was performed on an ABI Prism 7500 Real-Time PCR system (Thermo Fisher Scientific, Inc.). Primer sequences were as follows: NLRP3-forward, 5'-ATT ACCCGCCCGAGAAAGG-3', and reverse, 5'-CATGAGTGT GGCTAGATCCAAG-3'; IL-1 $\beta$ forward, 5'-GTACAAGGA GAACCAAGCAA-3' and reverse, 5'-CCGTCTTTCATTACA CAGGA-3'; IL-18 forward, 5'-AGGACACTTTCTTGCTTG CC-3', and reverse, 5'-CACAAACCCTCCCCACCTAA-3'; GAPDH forward 5'-TTCACCACCATGGAGAAGGC-3' and reverse 5'-GGCATGGACTGTGGTCATGA-3'.

NLRP3 gene knockdown. RAW 264.7 cells were nucleofected with $20 \mu \mathrm{M}$ NLRP3 specific small interfering (si)RNA (Shanghai Biotend, Shanghai, China) or negative control (NC) siRNA (Shanghai Biotend) using Lipofectamine 2000 (Invitrogen; Thermo Fisher Scientific, Inc.) according to the manufacturer's protocol. Nucleofected cells were incubated for $24 \mathrm{~h}$ at $37^{\circ} \mathrm{C}, 5 \% \mathrm{CO}_{2}$ and humidity in the presence or absence of leptin, $6 \mathrm{~h}$ post-transfection. Knockdown of the NLRP3 gene was determined via RT-qPCR with the following primers: NLRP3 siRNA forward, 5'-GCAGGUUCUACU CUAUCAAdTdT-3' and reverse, 5'-UUGAUAGAGUAGAAC CUGCdTdT-3'. The NC siRNA sequences were as follows: NC siRNA forward, 5'-UUCUCCGAACGUGUCACGUdTdT-3' and reverse, 5'-ACGUGACACGUUCGGAGAAdTdT-3'.

Statistical analysis. A paired t-test was employed for two group analyses and Kruskal-Wallis one-way analysis of variance was used for analyses of $>3$ groups using GraphPad Prism 5 software (GraphPad Software, Inc., La Jolla, CA, USA). Results are expressed as the mean \pm standard deviation. $\mathrm{P}<0.05$ was considered to indicate a statistically significant difference and the experiments were repeated three times.

\section{Results}

Leptin promotes IL-18 secretion in RAW 264.7 cells. To study the effects of leptin on macrophages, leptin was applied at increasing doses to RAW 264.7 cells for 24 h, using LPS and/or ATP as positive controls. Supernatants or cell sediments were collected and analyzed by ELISA or RT-qPCR. The present study reported a leptin-induced increase in IL-1 $\beta$ mRNA expression levels only, whereas a dose-dependent increase was observed in IL-18 mRNA and protein expression levels (Fig. 1)

Leptin activates caspase-1 and NLRP3 to promote IL-18 secretion. Caspase-1 contributes to the NLRP3 inflammasome complex and regulates the synthesis and secretion of IL-18 by proteolytically digesting pro-IL-18 $(17,18)$. Since leptin was observed to promote IL-18 secretion in RAW 264.7 cells, the effects of leptin on caspase-1 were investigated. The findings of the present study indicated that activation of 

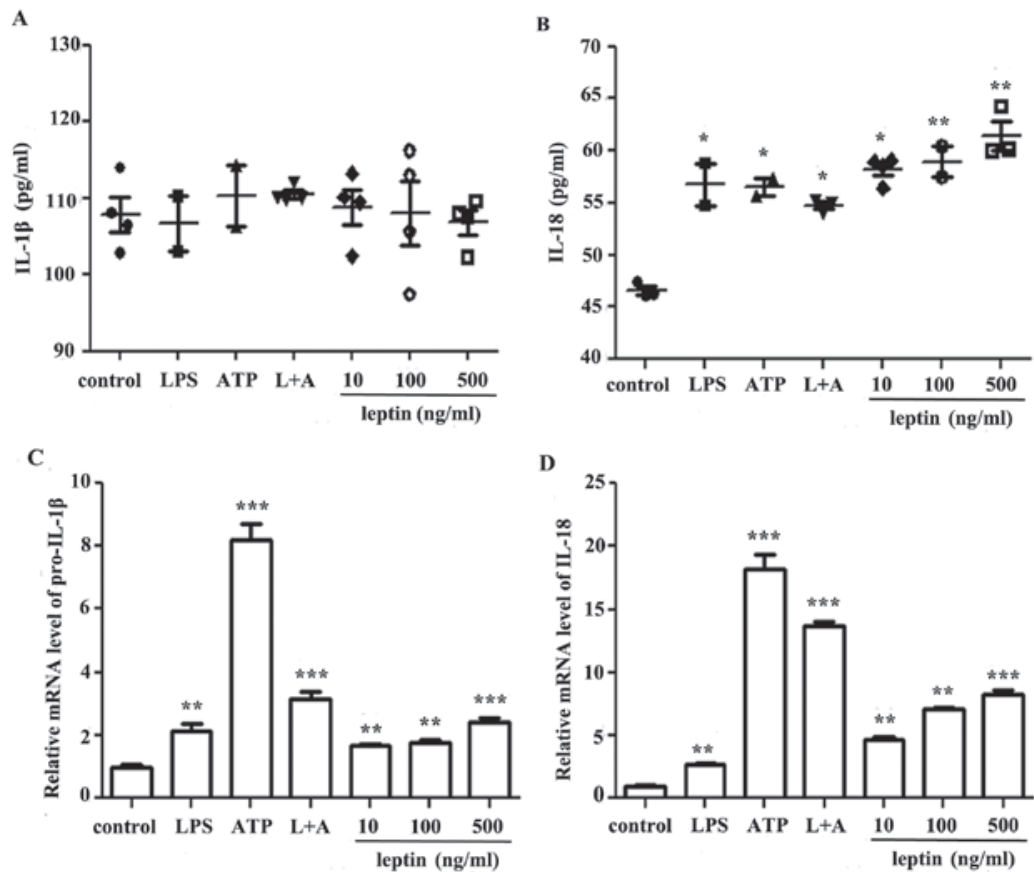

Figure 1. Leptin promotes IL-18, but not IL-1 $\beta$ secretion, in RAW 264.7 cells. (A) IL-1 $\beta$ and (B) IL-18 ELISA of culture supernatants from RAW 264.7 cells incubated with LPS, ATP, L+A or leptin at increasing doses $(10,100$ and $500 \mathrm{ng} / \mathrm{ml})$ for $24 \mathrm{~h}$. Results are presented as the mean \pm standard error of the mean from four independent experiments. Relative mRNA expression levels of (C) IL-1 $\beta$ and (D) IL-18 in RAW 264.7 cells treated as aforementioned. Results are from three independent experiments. ${ }^{*} \mathrm{P}<0.05,{ }^{* *} \mathrm{P}<0.01,{ }^{* * *} \mathrm{P}<0.001$ vs. the control. ATP, adenosine 5 'triphosphate; IL, interleukin; LPS, lipopolysaccharide; L+A, LPS and ATP.
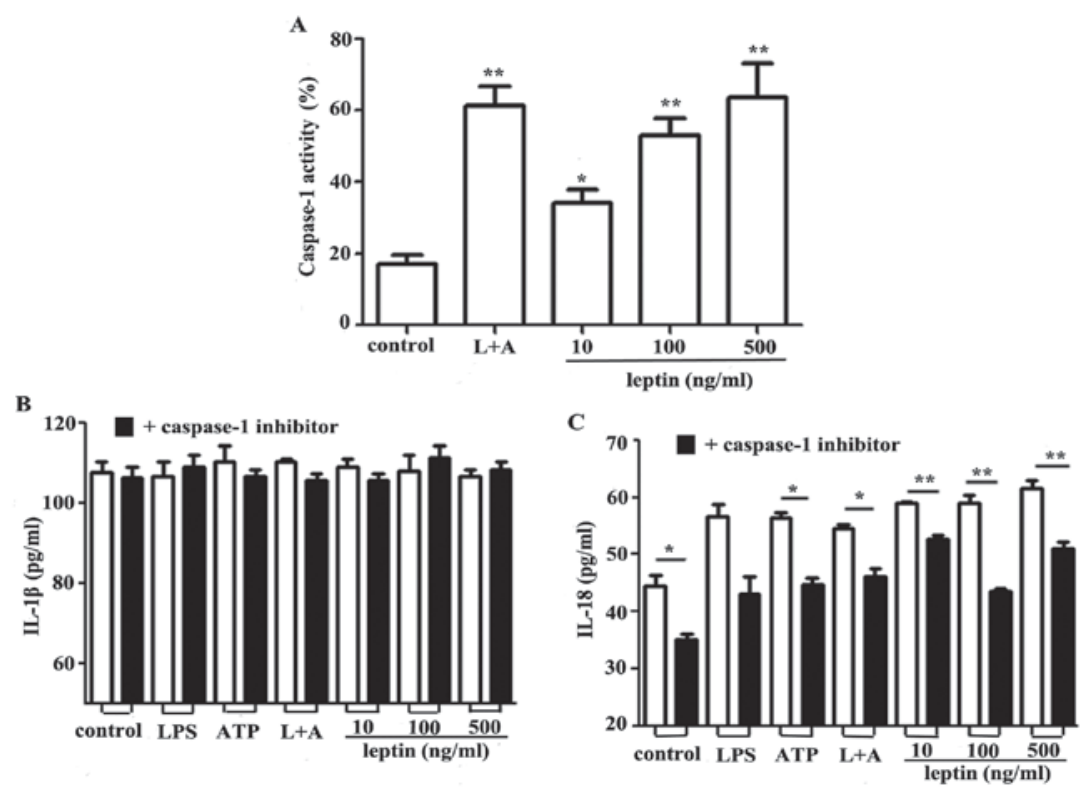

Figure 2. Caspase-1 activation facilitates IL-18 secretion in response to leptin. (A) Caspase-1 activity was measured by Fluorochrome-Labeled Inhibitor of Caspases staining of RAW 264.7 cells incubated with L+A or leptin at increasing doses $(10,100 \mathrm{and} 500 \mathrm{ng} / \mathrm{ml})$ for $24 \mathrm{~h}$. Cumulative data are from three experiments. (B) IL-1 $\beta$ and (C) IL-18 expression in the culture supernatants from RAW 264.7 cells following treatment with or without the caspase-1 inhibitor Ac-YVAD-cmk $(20 \mu \mathrm{M})$ for $24 \mathrm{~h}$, as determined by ELISA. Results are expressed as $\mathrm{pg} / \mathrm{ml}$ and are presented as the mean \pm standard error of the mean from four independent experiments. " $\mathrm{P}<0.05,{ }^{* *} \mathrm{P}<0.01$ vs. the control group. ATP, adenosine 5'triphosphate; IL, interleukin; LPS, lipopolysaccharide; L+A, LPS and ATP.

caspase-1 was induced by leptin in a dose-dependent manner (Fig. 2A). Inhibition of caspase-1 via Ac-YVAD-cmk had no effect on IL-1 $\beta$ secretion (Fig. 2B); however, IL-18 secretion was markedly decreased in response to the caspase-1 inhibitor (Fig. 2C).
The NLRP3 inflammasome comprises NLRP3, and the adapter and effector proteins, ASC and caspase-1, respectively. The effects of leptin on capsase- 1 activation prompted an investigation into the association between leptin and the NLRP3 inflammasome. The results demonstrated that leptin 

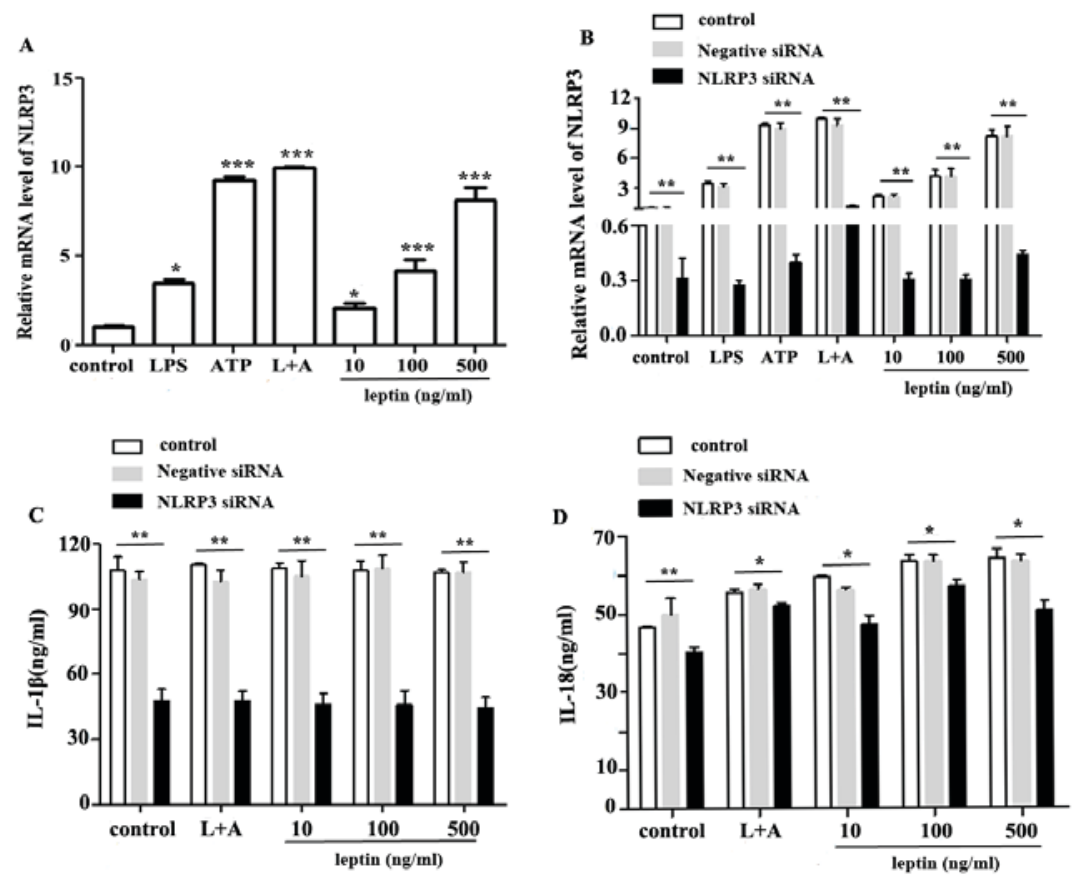

Figure 3. NLRP3 upregulation promotes IL-18 expression in response to leptin. (A) Relative mRNA expression levels of NLRP3 in RAW 264.7 cells incubated with LPS, ATP, L+A or leptin at increasing doses $(10,100$ and $500 \mathrm{ng} / \mathrm{ml})$ for $24 \mathrm{~h}$. (B) Relative mRNA expression levels of NLRP3 in RAW 264.7 cells following nucleofection with NLRP3 specific siRNA or negative control siRNA. (C) IL-1 $\beta$ or (D) IL-18 expression in the culture supernatants from RAW 264.7 cells treated as aforementioned, as determined by ELISA. ${ }^{*} \mathrm{P}<0.05,{ }^{* *} \mathrm{P}<0.01,{ }^{* * *} \mathrm{P}<0.001$ vs. the control. ATP, adenosine 5'triphosphate; IL, interleukin; LPS, lipopolysaccharide; L+A, LPS and ATP; NLRP3, nucleotide-binding oligomerization domain-like receptor family pyrin domain-containing 3; siRNA, small interfering RNA.

upregulated the mRNA expression levels of NLRP3 (Fig. 3A). Conversely, NLRP3, IL-1 $\beta$ and IL-18 expression levels were reduced following nucleofection with NLRP3-specific siRNA (Fig. 3B, C and D respectively).

ROS synthesis and $K^{+}$efflux is involved in leptin-induced $I L-18$. ROS have been reported to be key mediators in the activation of the NLRP3 inflammasome (19-21). Intracellular ROS generation was measured in response to leptin within RAW 264.7 cells. Leptin-induced ROS generation was observed compared with in the control group (Fig. 4A and B). In addition, a significant decrease in IL-18 production was observed in response to the NADPH oxidase inhibitor DPI (Fig. 4C).

Previous studies have suggested that $\mathrm{K}^{+}$efflux appears to be an important mediator in the activation of the NLRP3 inflammasome (22-24). RAW 264.7 cells were incubated with leptin at increasing doses for $24 \mathrm{~h}$ in the presence or absence of $100 \mathrm{mM} \mathrm{KCl}$. The results of the present study indicated that although IL-1 $\beta$ secretion was unaffected (Fig. 4D), an impairment in IL-18 secretion following elimination of $\mathrm{K}^{+}$efflux was observed (Fig. 4E).

\section{Discussion}

A previous study revealed that leptin induced the upregulation of phagocytic function-associated markers, and stimulated the secretion of proinflammatory cytokines, including TNF- $\alpha$, IL-6 and IL-12 (12). The results of the present study suggested an association between leptin-induced IL-18 secretion and activation of the NLRP3 inflammasome, via increases in ROS generation and $\mathrm{K}^{+}$efflux within RAW 264.7 cells. As a member of the IL-1 cytokine family, IL-18 possesses similarities to IL-1 with regards to structure and receptor utilization. IL-18 serves a key proinflammatory role by inducing interferon- $\gamma$ expression (25). The expression, synthesis and processing of IL-18 however, is distinct compared with other members of the IL-1 cytokine family (26-28) and is regulated by caspase-1. Following processing, IL-18 is released into the extracellular milieu and can also be expressed as a membrane-bound form. Active IL-18 attaches to the IL-18 receptor, which is expressed on various cells, including macrophages. Myeloid differentiation primary response gene 88-IRAF6-nuclear factor- $\kappa \mathrm{B}$ and signal transduction and activator of transcription 3-mitogen activated protein kinase signaling pathways are two major pathways for IL-18 (25). Recently, it has been reported that breast cancer cell metastasis may be associated with leptin-induced secretion of IL-18 (29), which requires future investigation.

In the present study, leptin was reported to increase IL-1 $\beta$ gene expression; however, protein secretion remained unaffected within RAW 264.7 cells. Additionally, IL-1 $\beta$ was unaffected by caspase-1 inhibition. Martin et al (7) detected IL-1 $\beta$ secretion within Th17 cells in a NLRP3-ASC-caspase-8-dependent manner in the absence of caspase-1. These findings suggested an association between caspase- 8 and the leptin-induced effects observed in macrophage cells. In addition, the secreted protein p60 from Listeria monocytogenes serves as a 'non-canonical' stimulus, which activates the NLRP3 inflammasome. In the present study, leptin mainly promoted IL-18 secretion and caspase-1 
$\mathbf{A}$
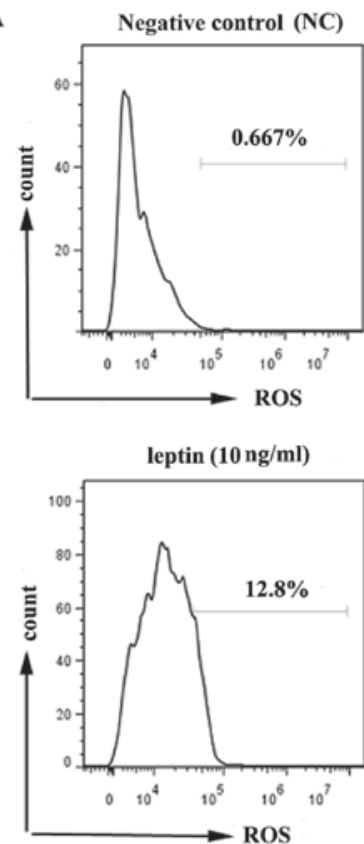

B
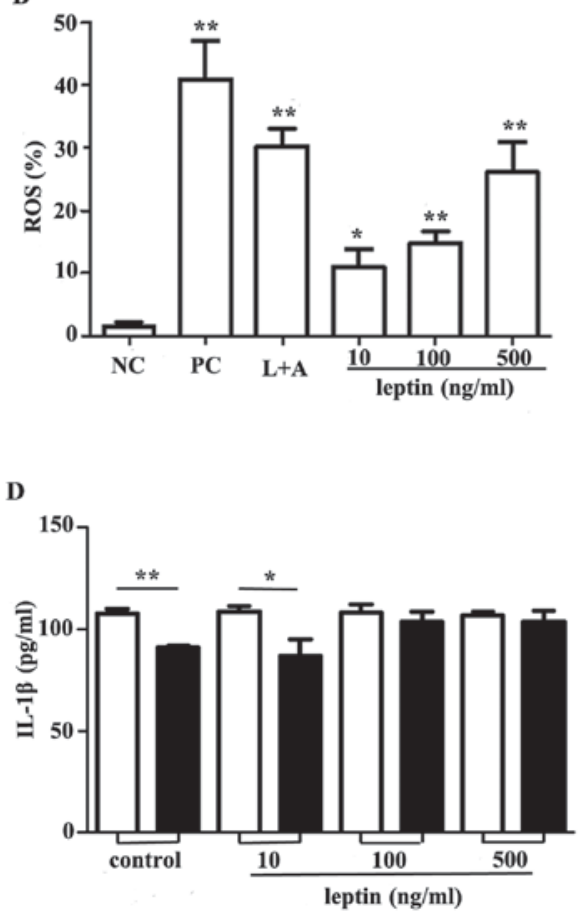

Positive control (PC)

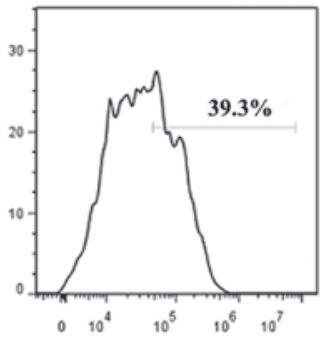

leptin $(100 \mathrm{ng} / \mathrm{ml})$
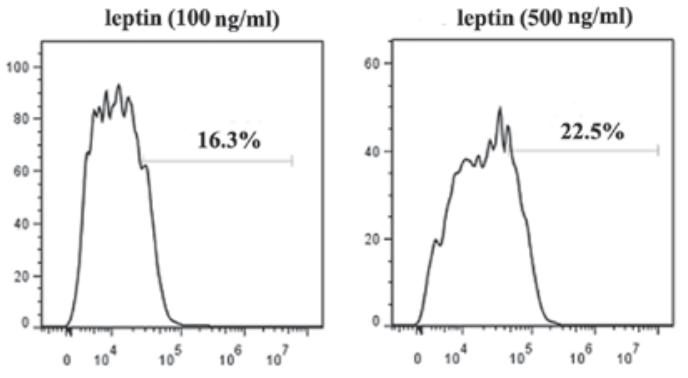

LPS + ATP

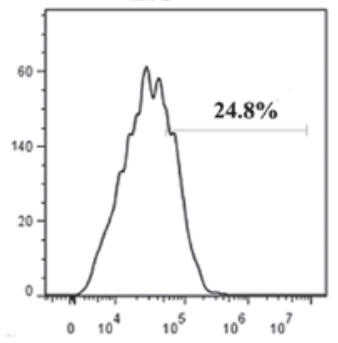

C
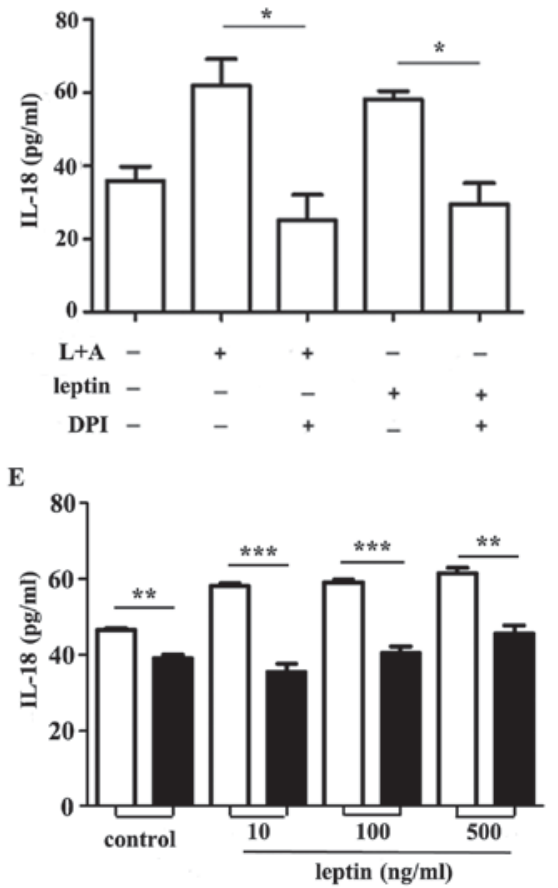

Figure 4. ROS synthesis and $\mathrm{K}^{+}$efflux is involved in producing IL-18 in response to leptin. (A) Flow cytometric analysis of ROS in RAW 264.7 cells incubated with leptin at increasing doses $(10,100$ and $500 \mathrm{ng} / \mathrm{ml})$ for $24 \mathrm{~h}$. THBP was used as a positive control. Representative data from three independent experiments are presented. (B) Cumulative data of ROS in RAW 264.7 cells from three experiments. (C) IL-18 ELISA of culture supernatants from RAW 264.7 cells incubated with leptin $(500 \mathrm{ng} / \mathrm{ml})$ for $24 \mathrm{~h}$ in the presence or absence of the ROS inhibitor DPI $(50 \mu \mathrm{M})$. (D) IL-1 $\beta$ or (E) IL-18 expression in the culture supernatants from RAW 264.7 cells incubated with leptin at increasing doses $(10,100$ and $500 \mathrm{ng} / \mathrm{ml})$ for $24 \mathrm{~h}$ in the presence or absence of $\mathrm{KCl}(100 \mathrm{mM})$, as determined by ELISA. ${ }^{*} \mathrm{P}<0.05,{ }^{* *} \mathrm{P}<0.01,{ }^{* * *} \mathrm{P}<0.001$ vs. the control. ATP, adenosine 5 'triphosphate; DPI, diphenyleneiodonium chloride; IL, interleukin; LPS, lipopolysaccharide; L+A, LPS and ATP; ROS, reactive oxygen species.

inhibitor mainly inhibited IL-18. It could be hypothesized that other caspases, such as caspase- 8 may influence IL-1 $\beta$ response to leptin. The production of IL- $1 \beta$ or IL-18 is independently regulated following activation of the inflammasome. Inhibitors of ROS production inhibited secretion of IL-1 $\beta$, but did not impair IL-18 secretion. Furthermore, DCs from caspase-11 (casp11)-deficient mice failed to secrete IL-1 $\beta$ in response to $p 63$ but were fully responsive for IL-18 secretion. Therefore, other disparate licensing factors may control IL-18 vs. IL-1 $\beta$ within dendritic cells (30). Consistent with previous studies of human monocytes, the present study demonstrated that leptin augmented the secretion of IL-18, but not IL-1 $\beta$ (31). Conversely, leptin has been reported to induce IL-1 $\beta$ secretion within human peripheral blood mononuclear cells (PBMCs) $(32,33)$; elevated IL-1 $\beta$ mRNA and IL-18 protein expression levels, and increased cytokine responses to 
LPS have also been observed in monocyte-derived dendritic cells (34). In addition, it has been reported that leptin may expedite IL-1 $\beta$ secretion within bovine PBMCs; however, it appears that the mRNA expression levels of IL- $1 \beta$ and IL-18 were unaffected (35). Therefore, these findings indicated that leptin-mediated responses within myeloid immune cells may differ between species, lineage and differentiation state.

Reactive oxygen species and $\mathrm{K}^{+}$efflux appear to be important mediators for the activation of the NLRP3 inflammasome. The present study revealed that leptin promotes IL-18 secretion by increasing ROS synthesis and $\mathrm{K}^{+}$efflux, which may activate the NLRP3 inflammasome in RAW 264.7 cells. Numerous studies have indicated that ROS and $\mathrm{K}^{+}$efflux may serve as strong activators for the NLRP3 inflammasome $(36,37)$.

In conclusion, the findings of the present study revealed that leptin promotes IL-18 secretion by enhancing ROS synthesis and $\mathrm{K}^{+}$efflux, which activates the NLRP3 inflammasome in RAW 264.7 cells. Leptin may therefore serve as a novel activator of the NLRP3 inflammasome through blocking leptin may be considered as a target for future antimicrobial and anti-inflammatory treatment.

\section{Acknowledgements}

The present study was supported by grants from the National Science Foundation for Young Scholars of China (grant no. 81401345) and the Young Physician Training Plan of North Huashan Hospital, Fudan University (grant no. 0000077).

\section{References}

1. Próchnicki T, Mangan MS and Latz E: Recent insights into the molecular mechanisms of the NLRP3 inflammasome activation. F1000Res 5: pii: F1000 Faculty Rev-1469, 2016.

2. Kim Y, Wang W, Okla M, Kang I, Moreau R and Chung SJ: Suppression of NLRP3 inflammasome by $\gamma$-tocotrienol ameliorates type 2 diabetes. Lipid Res 57: 66-76, 2016.

3. Shin MS, Kang Y, Lee N, Wahl ER, Kim SH, Kang KS, Lazova R and Kang I: Self double-stranded (ds)DNA induces IL-1 $\beta$ production from human monocytes by activating NLRP3 inflammasome in the presence of anti-dsDNA antibodies. J Immuno 190: 1407-1415, 2013.

4. Tschopp J and Schroder K: NLRP3 inflammasome activation: The convergence of multiple signalling pathways on ROS production? Nat Rev Immunol 10: 210-215, 2010.

5. Arbore G, West EE, Spolski R, Robertson AA, Klos A, Rheinheimer C, Dutow P, Woodruff TM, Yu ZX, O'Neill LA, et al: T helper 1 immunity requires complement-drivenNLRP3 inflammasome activity in $\mathrm{CD}^{+}{ }^{+} \mathrm{T}$ cells. Science 352: aad1210, 2016.

6. Bruchard M, Rebé C, Derangère V, Togbé D, Ryffel B, Boidot R, Humblin E, Hamman A, Chalmin F, Berger H, et al: The receptor NLRP3 is a transcriptional regulator of TH2 differentiation. Nat Immunol 16: 859-870, 2015.

7. Martin BN, Wang C, Zhang CJ, Kang Z, Gulen MF, Zepp JA, Zhao J, Bian G, Do JS, Min B, et al: T cell-intrinsic ASC critically promotes $\mathrm{T}(\mathrm{H}) 17$-mediated experimental autoimmune encephalomyelitis. Nat Immunol 17: 583-592, 2016.

8. Mortimer L, Moreau F, MacDonald JA and Chadee K: NLRP3 inflammasome inhibition is disrupted in a group of auto-inflammatory disease CAPS mutations. Nat Immunol 17: 1176-1186, 2016.

9. White CS, Lawrence CB, Brough D and Rivers-Auty J: Inflammasomes as therapeutic targets for Alzheimer's disease. Brain Pathol 27: 223-234, 2017.

10. Kim Y, Wang W, Okla M, Kang I, Moreau R and Chung S: Suppression of NLRP3 inflammasome by $\gamma$-tocotrienol ameliorates type 2 diabetes. J Lipid Res 57: 66-76, 2016.
11. Lu A, Li H, Niu J, Wu S, Xue G, Yao X, Guo Q, Wan N, Abliz P, Yang G, et al: Hyperactivation of the NLRP3 inflammasome in myeloid cells leads to severe organ damage in experimental lupus. J Immunol 198: 1119-1129, 2017.

12. Fernández-Riejos P, Najib S, Santos-Alvarez J, Martín-Romero C, Pérez-Pérez A, González-Yanes C and Sánchez-Margalet V: Role of leptin in the activation of immune cells. Mediators Inflamm 2010: 568343, 2010.

13. Yu Y, Liu Y, Shi FD, Zou H, Matarese G and La Cava A: Cutting edge: Leptin-induced ROR $\gamma \mathrm{t}$ Expression in $\mathrm{CD}^{+} \mathrm{T}$ cells promotes Th17 responses in systemic lupus erythematosus. Immunol 190: 3054-3058, 2013.

14. Liu Y, Yu Y, Matarese G and La Cava A: Cutting edge: Fasting-induced hypoleptinemia expands functional regulatory $\mathrm{T}$ cells in systemic lupuserythematosus. J Immunol 188: 2070-2073, 2012.

15. Wang X, Chrysovergis K, Kosak J and Eling TE: Lower NLRP3 inflammasome activity in NAG-1 transgenic mice is linked to a resistance to obesity and increased insulin sensitivity. Obesity (Silver Spring) 22: 1256-1263, 2014.

16. Livak KJ and Scmittgen TD: Analysis of relative gene expression data using real-time quantitative PCR and the 2(-Delta Delta C(T)) method. Methods 25: 402-408, 2001.

17. Gross O, Thomas CJ, Guarda G and Tschopp J: The inflammasome: An integrated view. Immunol Rev 243: 136-151, 2011.

18. Fu S, Xu L, Li S, Qiu Y, Liu Y, Wu Z, Ye C, Hou Y and Hu CA: Baicalin suppresses NLRP3 inflammasome and nuclear factor-kappa B (NF- $\kappa \mathrm{B})$ signaling during Haemophilus parasuis infection. Vet Res 47: 80, 2016.

19. Braga TT, Forni MF, Correa-Costa M, Ramos RN, Barbuto JA, Branco P, Castoldi A, Hiyane MI, Davanso MR, Latz E, et al: Soluble uric acid activates the NLRP3 inflammasome. Sci Rep 7: 39884, 2017.

20. Yin Y, Zhou Z, Liu W, Chang Q, Sun G and Dai Y: Vascular endothelial cells senescence is associated with NOD-like receptor family pyrin domain-containing 3 (NL RP3) inflammasome activation via reactive oxygen species (ROS)/thioredoxin-interacting protein (TXNIP) pathway. Int J Biochem Cell Biol 84: 22-34, 2017.

21. Toksoy A, Sennefelder H, Adam C, Hofmann S, Trautmann A, Goebeler M and Schmidt M: Potent NLRP3 inflammasome activation by the HIV reverse-transcriptase inhibitor abacavir. J Biol Chem 292: 2805-2814, 2017.

22. Kang MJ, Jo SG, Kim DJ and Park JH: NLRP3 inflammasome mediates interleukin-1 $\beta$ production in immune cells in response to Acinetobacter baumannii and contributes to pulmonary inflammation in mice. Immunology 150: 495-505, 2017.

23. Gong Z, Zhou J, Zhao S, Tian C, Wang P, Xu C, Chen Y, Cai W and $\mathrm{Wu}$ J: Chenodeoxycholic acid activates NLRP3 inflammasome and contributes to cholestatic liver fibrosis. Oncotarget 7: 83951-83963, 2016.

24. Groß CJ, Mishra R, Schneider KS, Médard G, Wettmarshausen J, Dittlein DC, Shi H, Gorka O, Koenig PA, Fromm S, et al: $\mathrm{K}^{+}$Efflux-Independent NLRP3 inflammasome activation by small molecules targeting mitochondria. Immunity 45 : 761-773, 2016.

25. Lee JH, Cho DH and Park HJ: IL-18 and Cutaneous Inflammatory Diseases. Int J Mol Sci 16: 29357-29369, 2015.

26. Sims JE and Smith DE: The IL-1 family: Regulators of immunity. Nat Rev Immunol 10: 89-102, 2010.

27. Puren AJ, Fantuzzi G and Dinarello CA: Gene expression, synthesis, and secretion of interleukin 18 and interleukin 1beta are differentially regulated in human blood mononuclear cells and mouse spleen cells. Proc Nat Acad Sci USA 96: 2256-2561, 1999.

28. Arend WP, Palmer G and Gabay C: IL-1, IL-18, and IL-33 families of cytokines. Immunol Rev 223: 20-38, 2008.

29. Li K, Wei L, Huang Y, Wu Y, Su M, Pang X, Wang N, Ji F, Zhong $\mathrm{C}$, Chen $\mathrm{T}$, et al: Leptin promotes breast cancer cell migration and invasion via IL-18 expression and secretion. Int J Oncol 48: 2479-2487, 2016.

30. Schmidt RL and Lenz LL: Distinct licensing of IL-18 and IL-1 $\beta$ secretion in response to NLRP3 inflammasome activation. PLoS One 7: e45186, 2012.

31. Jitprasertwong P, Jaedicke KM, Nile CJ, Preshaw PM and Taylor JJ: Leptin enhances the secretion of interleukin (IL)-18, but not IL-1 $\beta$, from human monocytes via activation of caspase-1. Cytokine 65: 222-230, 2014. 
32. Gabay C, Dreyer M, Pellegrinelli N, Chicheportiche R and Meier CA: Leptin directly induces the secretion of interleukin 1 receptor antagonist in human monocytes. J Clin Endocrinol Metab 86: 783-791, 2001

33. Dixit VD, Schaffer EM, Pyle RS, Collins GD, Sakthivel SK, Palaniappan R, Lillard JW Jr and Taub DD: Ghrelin inhibits leptin-and activation-induced proinflammatory cytokine expression by human monocytes and T cells. J Clin Invest 114: 57-66, 2004.

34. Mattioli B, Straface E, Quaranta MG, Giordani L and Viora M: Leptin promotes differentiation and survival of human dendritic cells and licenses them for Th1 priming. J Immunol 174: 6820-6828, 2005.
35. Ahmed M, Shaban Z, Yamaji D, Okamatsu-Ogura Y, Soliman M, Abd Eldaim M, Ishioka K, Makondo K, Saito M and Kimura K: Induction of proinflammatory cytokines and caspase-1 by leptin in monocyte/macrophages from holstein cows. J Vet Med Sci 69: 509-514, 2007.

36. Chen CY, Yang CH, Tsai YF, Liaw CC, Chang WY and Hwang TL: Ugonin U stimulates NLRP3 inflammasome activation and enhances inflammasome-mediated pathogen clearance. Redox Biol 11: 263-274, 2016.

37. Lordén G, Sanjuán-García I, de Pablo N, Meana C, Alvarez-Miguel I, Pérez-García MT, Pelegrín P, Balsinde J and Balboa MA: Lipin-2 regulates NLRP3 inflammasome by affecting P2X7 receptor activation. J Exp Med 214: 511-528, 2016. 